\title{
Clinicopathological characteristics, adjuvant chemotherapy decision and disease outcome in patients with breast cancer with a 21-gene recurrence score of 26-30
}

\author{
JING YU, JIAYI WU, OU HUANG, JIANRONG HE, LI ZHU, WEIGUO CHEN, \\ YAFEN LI, XIAOSONG CHEN and KUNWEI SHEN \\ Department of General Surgery, Comprehensive Breast Health Center, Ruijin Hospital, \\ Shanghai Jiao Tong University School of Medicine, Shanghai 200025, P.R. China
}

Received October 9, 2019; Accepted March 26, 2020

DOI: 10.3892/ol.2020.11734

\begin{abstract}
Recurrence score (RS) could be used to predict clinical outcomes and chemotherapy efficacy in patients with hormone receptor (HR)-positive, human epidermal growth factor receptor 2 (HER2)-negative and lymph node-negative breast cancer. However, the clinical features and management of patients with an RS of 26-30 are not completely understood. In the present study, 783 patients with $\mathrm{HR}^{+} / \mathrm{HER} 2-$, lymph node-negative early breast cancer and $\mathrm{RS} \geq 18$ were included and categorized into RS=18-25 (47.8\%), 26-30 (25.5\%) or $\geq 31$ (26.7\%) groups. Clinicopathological characteristics, adjuvant chemotherapy usage and disease outcomes were compared. Alterations in the adjuvant chemotherapy recommendation after 21-gene RS testing were also analyzed. The results indicated that patients with $\mathrm{RS}=26-30$ had higher progesterone receptor $(\mathrm{PR})$ expression [odds ratio $(\mathrm{OR})=2.84 ; \mathrm{P}<0.001$ ] and lower Ki-67 index $(\mathrm{OR}, 1.88 ; \mathrm{P}=0.032)$ compared with patients with $\mathrm{RS} \geq 31$. Multivariate analysis demonstrated that age $\leq 50$ years $(\mathrm{OR}, 5.75 ; \mathrm{P}=0.001)$ and luminal-B subtype $(\mathrm{OR}, 7.75 ; \mathrm{P}<0.001)$ were factors that were independently associated with chemotherapy usage in the $\mathrm{RS}=26-30$ group. Among 104 patients who were not recommended chemotherapy before 21-gene RS testing, the treatment decision for 52 patients was changed to recommend chemotherapy once an RS of 26-30 was identified. The patient adherence rate to the treatment recommendation was $95.0 \%$ (190/200). After a median follow-up of 21.5 months, 6 patients displayed disease recurrence in the $\mathrm{RS}=26-30$ group, and there was no significant
\end{abstract}

Correspondence to: Dr Xiaosong Chen or Dr Kunwei Shen, Department of General Surgery, Comprehensive Breast Health Center, Ruijin Hospital, Shanghai Jiao Tong University School of Medicine, 197 Ruijin Er Road, Shanghai 200025, P.R. China E-mail: chenxiaosong0156@hotmail.com

E-mail:kwshen@medmail.com.cn

Key words: breast cancer, 21-gene recurrence score, adjuvant chemotherapy, multidisciplinary team, disease outcome difference between patients receiving chemotherapy and patients not receiving chemotherapy. In conclusion, patients with $\mathrm{RS}=26-30$ had tumors with higher PR expression and lower Ki-67 index compared with those of patients with $\mathrm{RS} \geq 31$. Age, luminal subtype and RS testing influenced chemotherapy usage in patients with $\mathrm{RS}=26-30$; however, no significant benefit from adjuvant chemotherapy was observed in a short term of 2 years.

\section{Introduction}

In women, breast cancer is the most frequently diagnosed malignant disease, accounting for $25 \%$ of all cancer cases, and presenting the highest mortality rate worldwide (1). Chemotherapy can reduce the risk of 10 -year mortality by a third in patients with breast cancer (2). Approximately 60-75\% of patients have hormone receptor (HR)-positive breast cancer, for whom adjuvant endocrine therapy alone can significantly improve clinical outcomes (3). Traditionally, physicians make treatment decisions based on clinicopathological characteristics; however, in the past decades, several multigene signatures have been developed, which can provide more precise prognostic and predictive information for early-stage HR-positive breast cancer. Multigene signatures facilitate individualized treatment and decrease adjuvant chemotherapy usage in patients with breast cancer (4).

Among the identified multigene assays, the 21-gene recurrence score (RS) assay, which is composed of 16 cancer-related genes and 5 reference genes, is the most widely studied and used in the clinic (5). The 21-gene RS assay is performed on fixed, paraffin-embedded tumor tissues using reverse transcription-quantitative PCR (RT-qPCR). The 21-gene RS assay scores, ranging from 0 to 100, are classified into low-(RS <18), intermediate- $(18 \leq \mathrm{RS}<31)$ and high-(RS $\geq 31$ ) risk groups (5). Data from National Surgical Adjuvant Breast and Bowel Project (NSABP) B-14 trial showed that RS predicted distant recurrence for patients with HR-positive, human epidermal growth factor receptor 2 (HER2)-negative and lymph node-negative breast cancer who were treated with tamoxifen (5). The NSABP B-20 trial further demonstrated that patients in the high-risk group displayed a $27.6 \%$ decrease 
in the 10-year distant recurrence rate due to chemotherapy, which confirmed the necessity of adjuvant chemotherapy for patients with $\mathrm{RS} \geq 31$ (6). The Southwest Oncology Group-8814 and Eastern Cooperative Oncology Group E2197 studies extended the application of the 21-gene RS assay to the lymph node-positive population $(7,8)$. With robust prognostic and predictive value in breast cancer, the 21-gene RS assay has been recommended by clinical practice guidelines, including those published by the National Comprehensive Cancer Network (NCCN) (9), and has been increasingly used in the clinic worldwide.

To lower the risk of undertreatment, which was defined as controlling the 10-year recurrence risk of breast cancer at a distant site to 10 and $20 \%$ for each cutoff, respectively, the prospective trials TAILORx and West Germany Study Plan-B used the 21-gene RS assay with a different cutoff value compared with previous studies $(10,11)$. In the two aforementioned trials, the risk group classification criteria were as follows: Low $(\mathrm{RS}<11)$, intermediate $(11 \leq \mathrm{RS}<26)$ and high ( $R S \geq 26)$. The TAILORx trial reported that endocrine therapy alone resulted in improved disease-free survival for patients in the low-risk group (10). For patients with $\mathrm{RS}=11-25$, adjuvant chemotherapy did not provide additional survival benefits, especially for patients aged $>50$ years (12). Furthermore, for patients with $\mathrm{RS}=26-100$ receiving adjuvant chemotherapy, the clinical outcomes were improved compared with those of patients treated with endocrine therapy alone (13).

In the TAILORx study, patients with $\mathrm{RS} \geq 26$ received adjuvant chemotherapy (10); however, the NSABP B-20 study demonstrated that only patients with $\mathrm{RS} \geq 31$ tumors benefited the most from adjuvant chemotherapy (6). At present, there are limited data available on the clinicopathological features and treatment patterns of patients with $\mathrm{RS}=26-30$.

The present study evaluated the clinicopathological characteristics, adjuvant chemotherapy usage and disease outcomes of patients with $\mathrm{HR}^{+} / \mathrm{HER} 2^{-} /$lymph node- breast cancer with $\mathrm{RS}=26-30$ in comparison with those of patients with $\mathrm{RS}=18-25$ and $\mathrm{RS} \geq 31$. Furthermore, whether 21-gene RS testing lead to a treatment recommendation alteration was investigated. The aim of the present study was to demonstrate the clinical features and to identify the appropriate treatment decision for patients with $\mathrm{RS}=26-30$.

\section{Materials and methods}

Study population. Female patients diagnosed with invasive breast cancer who received surgery between January 2014 and December 2017 at Ruijin Hospital, Shanghai Jiaotong University School of Medicine (Shanghai, China) were retrospectively included in the present study. Data regarding clinicopathological characteristics, treatment decisions and survival events were retrieved from Shanghai Jiaotong University Breast Cancer Database. The present study was reviewed and approved by the Ethical Committee of Ruijin Hospital. The inclusion criteria were as follows: i) Primary invasive breast cancer; ii) HR positive and HER2 negative; iii) lymph node-negative; and iv) $\mathrm{RS} \geq 18$. The exclusion criteria were as follows: i) Male patients with breast cancer; and ii) patients with incomplete data for immunohistochemical (IHC) results, chemotherapy usage or survival.
Pathological, IHC analysis and 21-gene RS assay testing. Histopathological examination of tumor histological subtype, grade and presence of lymphovascular invasion was conducted by experienced pathologists at the Department of Pathology of Ruijin Hospital in concordance with the World Health Organization classification (14). The tumor tissue was fixed by $10 \%$ neutral buffered formalin at room temperature overnight before embedding in paraffin. The $4-\mu \mathrm{m}$-thick, formalin-fixed, paraffin-embedded (FFPE) tissue sections were incubated with the peroxidase-blocking solution (cat. no. S2023; Dako; Agilent Technologies, Inc.) for $3 \mathrm{~min}$ and blocked with the blocking solution (cat. no. X0909; Dako; Agilent Technologies, Inc.) for $10 \mathrm{~min}$ after dewaxing in xylene for $60 \mathrm{~min}$ and rehydration in a descending alcohol series (100, 95 and 75\%), all at room temperature. Subsequently, IHC staining of estrogen receptor (ER), progesterone receptor (PR) and Ki-67 index was automatically performed using a Ventana BenchMark XT system (Ventana Medical Systems, Inc.). Briefly, the FFPE tissue sections were incubated for $32 \mathrm{~min}$ at $42^{\circ} \mathrm{C}$ with primary antibodies targeted against ER (cat. no. IR657; clone 1D5; 1:100; rabbit monoclonal), PR (cat. no. IR068; clone PR636; 1:100; mouse monoclonal) and Ki-67 (cat. no. IR626; clone MIB-1; 1:100; mouse monoclonal) (all Dako; Agilent Technologies, Inc.). Subsequently, tissue sections were incubated with secondary goat anti-mouse (cat. no. P0447) or goat anti-rabbit (cat. no. P0448) (both 1:100; Dako; Agilent Technologies, Inc.) antibodies for $30 \mathrm{~min}$ at room temperature. A Dako automated immunohistochemistry system (Dako; Agilent Technologies, Inc.) was used to interpret the IHC results, which were checked by two experienced pathologists using a light microscope (magnification, $\mathrm{x} 100$ ). $\mathrm{ER}^{+}$and $\mathrm{PR}^{+}$tumors were defined as tumors with nuclear staining in $\geq 1 \%$ of tumor cells. Ki-67 index was assessed in $\geq 1,000$ invasive tumor cells, and was characterized as the proportion of positively stained cells in the nucleus vs. the total number of cells in the field. Luminal subtype was determined according to the St Gallen 2013 expert panel (15). Luminal A-like subtype was defined as $\mathrm{ER}^{+}, \mathrm{PR} \geq 20 \%$ and $\mathrm{Ki}-67<14 \%$, while luminal B-like was defined as $\mathrm{ER}^{+}$and $\mathrm{PR}<20 \%$ or $\mathrm{Ki}-67 \geq 14 \%$. The 21 -gene RS assay was performed on formalin-fixed, paraffin-embedded tissue sections as described in our previous study (16). The amount of tissue was determined by assessing the percentage of tumor on hematoxylin and eosin-stained slides. Briefly, the tissue slides were stained with Harris hematoxylin solution for $10 \mathrm{~min}$ and then differentiated in $1 \%$ acid alcohol, all at room temperature. Following bluing, eosin solution was used for counterstaining for $30 \mathrm{sec}$ at room temperature, and then slides were dehydrated in 95 and $100 \%$ alcohol, washed in xylene and mounted using a neutral balsam (data not shown). Total RNA was extracted using the RNeasy FFPE RNA kit (Qiagen $\mathrm{GmbH}$ ) from two $10-\mu \mathrm{m}$ unstained sections and was measured after verifying the absence of DNA contamination, which was assessed by a quantitative (q)PCR assay for $\beta$-actin DNA. Gene-specific reverse transcription was performed at $65^{\circ} \mathrm{C}$ for $5 \mathrm{~min}$ and $37^{\circ} \mathrm{C}$ for $60 \mathrm{~min}$ using the Omniscript RT kit (Qiagen $\mathrm{GmbH})$. Subsequently, standardized qPCR was performed using Premix Ex Taq ${ }^{\mathrm{TM}}$ (Takara Bio, Inc.) in 96-well plates using an Applied Biosystems 7500 Real-Time PCR system (Thermo Fisher Scientific, Inc.), with the following thermocycling conditions: $95^{\circ} \mathrm{C}$ for $10 \mathrm{~min}, 95^{\circ} \mathrm{C}$ 
for $20 \mathrm{sec}$ and $60^{\circ} \mathrm{C}$ for $45 \mathrm{sec}$ (for 40 cycles). The primers and probes used for qPCR are listed in Table SI. The expression levels of each cancer-associated gene were measured in triplicate and normalized to 5 reference genes, including ACTB, GAPD, GUSB, RPLP0 and TFRC. The RS was calculated using a specific algorithm as previously described (5). For patients with ipsilateral multifocal or bilateral invasive cancer, the highest RS was recorded.

Treatment decision and prognosis information. After surgery, the multidisciplinary team (MDT), which consisted of breast surgeons, medical oncologists, pathologists, radiation oncologists and specialized breast nurses, discussed and determined the appropriate adjuvant treatment recommendations for each patient. In the first-round of MDT voting, a primary chemotherapy recommendation was made based on standard clinicopathological and IHC results, which was recorded as the chemotherapy recommendation pre-RS assay. After obtaining the result of the 21-gene RS assay, the second-round of MDT voting was organized to determine the final decision, which was recorded as the chemotherapy recommendation post-RS assay. In both rounds of voting, if the vote was not unanimous, the decision of the attending physician who performed the surgery was recorded. The actual chemotherapy usage was confirmed during follow-up. The most frequently used chemotherapy regimens included docetaxel plus cyclophosphamide, epirubicin plus cyclophosphamide and epirubicin plus cyclophosphamide followed by docetaxel.

Statistical analysis. All clinicopathological characteristics were presented as patient number and percentage [n, (\%)] and analyzed as categorical variables. The $\chi^{2}$ test was used to evaluate the RS distribution and chemotherapy usage in patients with different clinicopathological characteristics, and Fisher's exact test was performed when had expected values less than 5. Multiple logistic regression models were used to generate adjusted odds ratios (ORs) with $95 \%$ confidence intervals (CIs) to assess factors associated with RS distribution and chemotherapy. Kaplan-Meier with Tarone-Ware tests (17) was used to compare the recurrence-free survival rate, and pairwise comparisons were performed for the recurrence-free survival. Recurrence events included local, regional, distant and contralateral breast recurrence. $\mathrm{P}<0.05$ was considered to indicate a statistically significant difference. Statistical analyses were performed using SPSS software (version 22.0; IBM Corp.).

\section{Results}

Baseline clinicopathological characteristics. A total of 821 patients diagnosed between January 2014 and December 2017 were reviewed, of which, 38 were excluded and 783 were included in the present study. The number of patients in the $\mathrm{RS}=18-25,=26-30$ and $\geq 31$ groups was 374 (47.8\%), 200 (25.5\%) and 209 (26.7\%), respectively. Baseline clinicopathological characteristics are presented in Table I. The mean age of the patients was $56.0 \pm 12.4$ years, and $511(65.3 \%)$ patients were aged $>50$ years. A total of $565(72.2 \%)$ patients had tumors $\leq 2 \mathrm{~cm}$ in size. Additionally, 138 (17.6\%) patients had grade-III tumors. The proportion of patients with $\mathrm{ER} \geq 50 \%$,
$\mathrm{PR} \geq 20 \%$ and $\mathrm{Ki}-67 \geq 14 \%$ was $96.6,63.9$ and $53.0 \%$, respectively. Furthermore, $562(71.8 \%)$ patients had luminal B-like breast cancer.

Clinicopathological characteristics of the different $R S$ groups. Univariate analysis indicated that age $(\mathrm{P}=0.030)$, tumor grade $(\mathrm{P}<0.001)$, ER status $(\mathrm{P}=0.001)$, $\mathrm{PR}$ status $(\mathrm{P}<0.001)$, Ki-67 index $(\mathrm{P}<0.001)$ and luminal subtype $(\mathrm{P}<0.001)$ were significantly different among the three RS groups (Table I). Grade-III tumors were present in $10.7,17.0$ and $30.6 \%$ of patients in the $\mathrm{RS}=18-25,=26-30$ and $\geq 31$ groups, respectively. Regarding luminal subtype, the $\mathrm{RS}=18-25,=26-30$ and $\geq 31$ groups contained 59.1, 75.5 and $90.9 \%$ luminal B-like tumors, respectively (Table I).

Multivariate analysis demonstrated that tumor grade, PR expression and $\mathrm{Ki}-67$ index were independently associated with RS grouping $(\mathrm{P}<0.05)$. Compared with the RS $\geq 31$ group, the $R S=26-30$ group was associated with higher PR expression (OR, 2.84; 95\% CI, 1.69-4.79; $\mathrm{P}<0.001)$ and lower Ki-67 index (OR, 1.88; 95\% CI, 1.06-3.34; $\mathrm{P}=0.032$ ), and tended to display fewer grade-III tumors (OR, 1.63; $95 \%$ CI, 0.96-2.76; $\mathrm{P}=0.070)$. There was no significant difference between the $\mathrm{RS}=18-25$ and $=26-30$ groups in terms of grade $(\mathrm{P}=0.133), \mathrm{PR}$ expression $(\mathrm{P}=0.063)$ or $\mathrm{Ki}-67$ index $(\mathrm{P}=0.924$; Table II $)$.

Adjuvant chemotherapy usage in the different RS groups. A total of $115(30.7 \%), 140(70.0 \%)$ and $186(89.0 \%)$ patients in the $\mathrm{RS}=18-25,=26-30$ and $\geq 31$ groups, respectively, received chemotherapy $(\mathrm{P}<0.001)$. Table III presents the clinicopathological parameters associated with chemotherapy usage in the whole population.

Multivariate analysis indicated that menstruation (OR, 2.55; 95\% CI, 1.62-4.02; $\mathrm{P}<0.001)$, larger tumor size (OR, 1.91; 95\% CI, 1.23-2.98; $\mathrm{P}=0.004)$, histological grade III (OR, 2.35; 95\% CI, 1.25-4.40; $\mathrm{P}=0.008)$, higher $\mathrm{Ki}-67$ index $(\mathrm{OR}, 2.59$; 95\% CI, 1.40-4.81; $\mathrm{P}=0.002)$, luminal B-like tumor $(\mathrm{OR}, 2.29$; 95\% CI, 1.09-4.83; $\mathrm{P}=0.029)$ and $\mathrm{RS}$ category $(\mathrm{P}<0.001)$ were independently associated with chemotherapy usage. Compared with patients with $\mathrm{RS}=18-25$, patients with $\mathrm{RS}=26-30$ (OR, 7.20; 95\% CI, 4.55-11.42; $\mathrm{P}<0.001)$ or $\mathrm{RS} \geq 31$ (OR, 16.08; 95\% CI, 9.19-28.14; $\mathrm{P}<0.001)$ were more likely to receive adjuvant chemotherapy. Furthermore, patients with comorbidities received chemotherapy less often compared with patients without comorbidities (OR, 0.52; 95\% CI, 0.34-0.79; $\mathrm{P}=0.002$; Table IV).

In the $\mathrm{RS}=18-25$ group, distribution of age, menstrual status, comorbidity, lymphovascular invasion, tumor size, histological type, tumor grade, PR status, Ki-67 index and luminal subtype were significantly different between patients receiving adjuvant chemotherapy and those not receiving it (Table SII). Multivariate analyses demonstrated that menstruation (OR, 2.53; 95\% CI, 1.38-4.65; $\mathrm{P}=0.003)$, larger tumor size (OR, 2.21; 95\% CI, 1.20-4.09; $\mathrm{P}=0.011)$, grade-III tumors $(\mathrm{OR}$, 2.75; 95\% CI, 1.18-6.44; P=0.019), PR <20\% (OR, 4.36; 95\% CI, 2.24-8.48; $\mathrm{P}<0.001)$ and $\mathrm{Ki}-67 \geq 14 \%$ (OR, 6.90; 95\% CI, 3.83-12.46; $\mathrm{P}<0.001)$ were factors independently associated with chemotherapy usage (Table SIII).

In the $\mathrm{RS} \geq 31$ group, univariate analysis indicated that younger age $(97.0 \%$ vs. $85.2 \%$; $\mathrm{P}=0.009)$, menstruation (97.0\% vs. $85.2 \%$; $\mathrm{P}=0.009)$, no comorbidity $(94.6 \%$ vs. $79.7 \%$; 
Table I. Clinicopathological characteristics of patients according to 21-gene RS classification.

\begin{tabular}{|c|c|c|c|c|c|}
\hline Variable & $\begin{array}{l}\text { Total, } \mathrm{n}(\%) \\
\quad(\mathrm{n}=783)\end{array}$ & $\begin{array}{c}\mathrm{RS}=18-25, \mathrm{n}(\%) \\
(\mathrm{n}=374,47.8 \%)\end{array}$ & $\begin{aligned} \mathrm{RS} & =26-30, \mathrm{n}(\%) \\
(\mathrm{n} & =200,25.5 \%)\end{aligned}$ & $\begin{array}{l}\mathrm{RS} \geq 31, \mathrm{n}(\%) \\
(\mathrm{n}=209,26.7 \%)\end{array}$ & P-value \\
\hline Age (years) & & & & & 0.030 \\
\hline$\leq 50$ & $272(34.7)$ & $147(39.3)$ & $58(29.0)$ & $67(32.1)$ & \\
\hline$>50$ & $511(65.3)$ & $227(60.7)$ & $142(71.0)$ & $142(67.9)$ & \\
\hline BMI & & & & & 0.740 \\
\hline$<25$ & $585(74.7)$ & $284(75.9)$ & $148(74.0)$ & $153(73.2)$ & \\
\hline$\geq 25$ & $198(25.3)$ & $90(24.1)$ & $52(26.0)$ & $56(26.8)$ & \\
\hline Comorbidity & & & & & 0.286 \\
\hline No & $456(58.2)$ & $217(58.0)$ & $91(45.5)$ & $130(62.2)$ & \\
\hline Yes & 327 (41.8) & $157(42.0)$ & $109(54.5)$ & $79(37.8)$ & \\
\hline Tumor size (cm) & & & & & 0.206 \\
\hline$\leq 2$ & $565(72.2)$ & $281(75.1)$ & $139(69.5)$ & $145(69.4)$ & \\
\hline$>2$ & $218(27.8)$ & 93 (24.9) & $61(30.5)$ & $64(30.6)$ & \\
\hline Histological type & & & & & 0.123 \\
\hline IDC & $650(83.0)$ & $301(80.5)$ & $167(83.5)$ & $182(87.1)$ & \\
\hline Non-IDC & $133(17.0)$ & $73(19.5)$ & $33(16.5)$ & $27(12.9)$ & \\
\hline Tumor grade & & & & & $<0.001$ \\
\hline $\mathrm{I} / \mathrm{II}$ & $524(66.9)$ & $268(71.7)$ & $135(67.5)$ & $121(57.9)$ & \\
\hline III & 138 (17.6) & $40(10.7)$ & $34(17.0)$ & $64(30.6)$ & \\
\hline Unknown & $121(15.5)$ & $66(17.6)$ & $31(15.5)$ & $24(11.5)$ & \\
\hline LVI & & & & & 0.994 \\
\hline Yes & $38(4.9)$ & $18(4.8)$ & $10(5.0)$ & $10(4.8)$ & \\
\hline No & 745 (95.1) & $356(95.2)$ & $190(95.0)$ & 199 (95.2) & \\
\hline ER status $(\%)$ & & & & & 0.001 \\
\hline$<50$ & $27(3.4)$ & 7 (1.9) & $4(2.0)$ & $16(7.7)$ & \\
\hline$\geq 50$ & 756 (96.6) & $367(98.1)$ & $196(98.0)$ & $193(92.3)$ & \\
\hline PR status $(\%)$ & & & & & $<0.001$ \\
\hline$<20$ & $283(36.1)$ & $82(21.9)$ & $75(37.5)$ & $126(60.3)$ & \\
\hline$\geq 20$ & $500(63.9)$ & $292(78.1)$ & $125(62.5)$ & $83(39.7)$ & \\
\hline Ki-67 index (\%) & & & & & $<0.001$ \\
\hline$<14$ & $368(47.0)$ & 209 (55.9) & $95(47.5)$ & $64(30.6)$ & \\
\hline$\geq 14$ & $415(53.0)$ & $165(44.1)$ & $105(52.5)$ & $145(69.4)$ & \\
\hline Luminal subtype & & & & & $<0.001$ \\
\hline Luminal A-like & $221(28.2)$ & $153(40.9)$ & $49(24.5)$ & $19(9.1)$ & \\
\hline Luminal B-like & $562(71.8)$ & $221(59.1)$ & $151(75.5)$ & 190 (90.9) & \\
\hline Surgery type & & & & & 0.346 \\
\hline BCS & $371(47.4)$ & $172(46.0)$ & $91(45.5)$ & $108(51.7)$ & \\
\hline Mastectomy & $412(52.6)$ & $202(54.0)$ & $109(54.5)$ & $101(48.3)$ & \\
\hline
\end{tabular}

Data were analyzed using the $\chi^{2}$ test. RS, recurrence score; BMI, body mass index; IDC, invasive ductal carcinoma; LVI, lymphovascular invasion; ER, estrogen receptor; PR, progesterone receptor; BCS, breast conserving surgery.

$\mathrm{P}<0.001)$ and infiltrating ductal carcinoma $(91.8 \%$ vs. $70.4 \%$; $\mathrm{P}=0.001$ ) were associated with adjuvant chemotherapy administration (Table SIV). Multivariate analysis also indicated that the aforementioned factors were independently associated with chemotherapy usage (Table SV).

Adjuvant chemotherapy usage in patients with $R S=26-30$. The baseline characteristics of patients with $\mathrm{RS}=26-30$ are presented in Table V. According to the results of the univariate analysis, younger age $(\mathrm{P}=0.012)$, menstruation $(\mathrm{P}=0.022)$, larger tumors $(\mathrm{P}=0.009)$, grade-III tumors $(\mathrm{P}<0.001)$, high-level Ki-67 index $(\mathrm{P}<0.001)$ and luminal $\mathrm{B}-$ like tumors $(\mathrm{P}<0.001)$ were associated with chemotherapy. Chemotherapy use was higher in patients aged $\leq 50$ years $(48 / 58 ; 82.5 \%)$ compared with patients aged $>50$-years (92/142; 64.8\% ; Fig. 1). Besides, among 151 patients with luminal B-like breast cancer, $120(79.5 \%)$ patients received 
Table II. Baseline characteristics stratified by 21-gene RS classification, with RS=26-30 as a reference.

\begin{tabular}{|c|c|c|c|c|c|c|c|}
\hline \multirow[b]{2}{*}{ Variable } & \multicolumn{3}{|c|}{$\mathrm{RS}=18-25(\mathrm{n}=374)$} & \multicolumn{3}{|c|}{$\mathrm{RS} \geq 31(\mathrm{n}=209)$} & \multirow[b]{2}{*}{ P-value } \\
\hline & OR & $95 \% \mathrm{CI}$ & P-value & OR & $95 \% \mathrm{CI}$ & P-value & \\
\hline Age (years) & & & 0.111 & & & 0.142 & 0.209 \\
\hline$\leq 50$ & 1.37 & $0.93-2.02$ & & 1.41 & $0.89-2.23$ & & \\
\hline$>50$ & 1 & & & 1 & & & \\
\hline Tumor grade & & & & & & & 0.007 \\
\hline $\mathrm{I} / \mathrm{II}$ & 1 & & & 1 & & & \\
\hline III & 0.67 & $0.39-1.13$ & 0.133 & 1.63 & $0.96-2.76$ & 0.070 & \\
\hline Unknown & 1.07 & $0.66-1.74$ & 0.781 & 0.90 & $0.49-1.64$ & 0.724 & \\
\hline ER status $(\%)$ & & & 0.888 & & & 0.113 & 0.138 \\
\hline$<50$ & 1.10 & $0.31-3.94$ & & 2.54 & $0.80-8.04$ & & \\
\hline$\geq 50$ & 1 & & & 1 & & & \\
\hline PR status (\%) & & & 0.063 & & & $<0.001$ & $<0.001$ \\
\hline$<20$ & 0.61 & $0.37-1.03$ & & 2.84 & $1.69-4.79$ & & \\
\hline$\geq 20$ & 1 & & & 1 & & & \\
\hline Ki-67 index (\%) & & & 0.924 & & & 0.032 & 0.032 \\
\hline$<14$ & 1 & & & 1 & & & \\
\hline$\geq 14$ & 0.97 & $0.55-1.72$ & & 1.88 & $1.06-3.34$ & & \\
\hline Luminal subtype & & & 0.212 & & & 0.950 & 0.342 \\
\hline Luminal A-like & 1 & & & 1 & & & \\
\hline Luminal B-like & 0.65 & $0.33-1.28$ & & 1.03 & $0.45-2.35$ & & \\
\hline
\end{tabular}

RS, recurrence score; OR, odds ratio; CI, confidence interval; ER, estrogen receptor; PR, progesterone receptor.

chemotherapy, which was higher compared with patients in the luminal-A cohort (40.8\%; Fig. 2).

Multivariate analysis demonstrated that age and luminal subtype were independent factors associated with adjuvant chemotherapy usage. Patients aged $\leq 50$ years were more likely to receive adjuvant chemotherapy compared with patients aged $>50$ years $(\mathrm{OR}, 5.75 ; 95 \% \mathrm{CI}, 2.08-15.90 ; \mathrm{P}=0.001)$. Compared with patients with luminal A-like tumors, a higher number of patients with luminal B-like tumors received adjuvant chemotherapy (OR, 7.75; 95\% CI, 3.28-18.32; P<0.001; Table SVI).

Alteration to chemotherapy recommendation after 21-gene $R S$ in patients with $R S=26-30$. A total of 200 patients with $\mathrm{RS}=26-30$ underwent two rounds of MDT recommendations. Before 21-gene RS testing, endocrine therapy alone was recommended by the MDT for $104(52.0 \%)$ patients, while chemoendocrine therapy was suggested for the remaining 96 (48.0\%) patients. After RS testing, the adjuvant regimen of $54(27.0 \%)$ patients was altered: 52 patients shifted from no chemotherapy to chemotherapy, and 2 patients shifted from chemotherapy to no chemotherapy (Table VI and Fig. 3).

Regarding the actual adjuvant treatment usage, 10 patients did not follow the treatment recommendation; therefore, the rate of adherence to MDT recommendations was 95.0\% (190/200; Table VI). A total of 146 patients received a recommendation for adjuvant chemotherapy after the RS assay; however, only $138(94.5 \%)$ patients received chemotherapy. The eight patients who did not adhere to the MDT recommendations displayed tumors with high ER expression and low Ki-67 index, which were primarily T1-stage and grade I/II tumors (Table SVII).

Adjuvant chemotherapy usage and disease outcomes. After a median follow-up of 21.5 months (range, 2-54 months), 13 (1.7\%) patients experienced disease recurrence, including 6 locoregional, 4 distant and 3 contralateral breast recurrences. In the $\mathrm{RS}=18-25,=26-30$ and $\geq 31$ groups, there were 3, 6 and 4 patients, respectively (Table SVIII), with disease recurrence ( $\mathrm{P}=0.183$; Fig. 4). Pairwise comparison indicated that there were no significantly different clinical outcomes between each pair of groups (data not shown). In the $\mathrm{RS}=26-30$ group, 4 patients with disease relapse received chemotherapy, and there was no significant difference compared with patients not receiving chemotherapy ( 2 patients; $\mathrm{P}=0.764$; Table SVIII).

\section{Discussion}

The present study included 783 patients with $\mathrm{HR}^{+} / \mathrm{HER} 2^{-} /$lymph node ${ }^{-}$breast cancer with $\mathrm{RS} \geq 18$, and indicated that patients with $\mathrm{RS}=26-30$ displayed higher $\mathrm{PR}$ expression and lower $\mathrm{Ki}-67$ index compared with patients with $\mathrm{RS} \geq 31$. Multivariate analysis suggested that age $\leq 50$ years and luminal B-like tumors were independently associated with chemotherapy usage in the $\mathrm{RS}=26-30$ group. After 21-gene RS testing and MDT discussion, the chemotherapy usage in patients with $\mathrm{RS}=26-30$ increased, and a high adjuvant chemotherapy compliance rate of $95.0 \%$ was 
Table III. Clinicopathological characteristics according to chemotherapy usage in the overall population.

\begin{tabular}{|c|c|c|c|c|}
\hline Variable & Total, $\mathrm{n}(\%)(\mathrm{n}=783)$ & Chemo, n $(\%)(\mathrm{n}=441)$ & Non-chemo, $n(\%)(n=342)$ & $\mathrm{P}$-value \\
\hline Age (years) & & & & 0.004 \\
\hline$\leq 50$ & $272(34.7)$ & $172(63.2)$ & $100(36.8)$ & \\
\hline$>50$ & $511(65.3)$ & $269(61.0)$ & $242(70.8)$ & \\
\hline Menstrual status & & & & 0.002 \\
\hline Premenopausal & $287(36.7)$ & $182(63.4)$ & $105(36.6)$ & \\
\hline Postmenopausal & $496(63.3)$ & $259(52.2)$ & $237(47.8)$ & \\
\hline Comorbidity & & & & $<0.001$ \\
\hline No & $456(58.2)$ & $287(62.9)$ & $169(37.1)$ & \\
\hline Yes & $327(41.8)$ & $154(47.1)$ & $173(52.9)$ & \\
\hline Surgery type & & & & 0.891 \\
\hline $\mathrm{BCS}$ & $371(47.4)$ & $208(56.1)$ & $163(43.9)$ & \\
\hline Mastectomy & $412(52.6)$ & $233(56.6)$ & $179(43.4)$ & \\
\hline Tumor size (cm) & & & & $<0.001$ \\
\hline$\leq 2$ & $565(72.2)$ & $296(52.4)$ & $269(47.6)$ & \\
\hline$>2$ & $218(27.8)$ & $145(66.5)$ & $73(33.5)$ & \\
\hline Histological type & & & & $<0.001$ \\
\hline IDC & $650(83.0)$ & $397(61.1)$ & $253(38.9)$ & \\
\hline Non-IDC & $133(17.0)$ & $44(33.1)$ & $89(66.9)$ & \\
\hline Tumor grade & & & & $<0.001$ \\
\hline $\mathrm{I} / \mathrm{II}$ & $524(66.9)$ & $280(53.4)$ & $244(46.6)$ & \\
\hline III & 138 (17.6) & $120(87.0)$ & $18(13.0)$ & \\
\hline Unknown & $121(15.5)$ & $41(33.9)$ & $80(66.1)$ & \\
\hline LVI & & & & 0.027 \\
\hline Yes & $38(4.9)$ & $28(73.7)$ & $10(26.3)$ & \\
\hline No & $745(95.1)$ & $413(55.4)$ & $332(44.6)$ & \\
\hline ER status (\%) & & & & 0.008 \\
\hline$<50$ & $27(3.4)$ & $22(81.5)$ & $5(18.5)$ & \\
\hline$\geq 50$ & $756(96.6)$ & 419 (55.9) & $330(44.1)$ & \\
\hline PR status (\%) & & & & $<0.001$ \\
\hline$<20$ & $283(36.1)$ & $202(71.4)$ & $81(28.6)$ & \\
\hline$\geq 20$ & $500(63.9)$ & 198 (39.6) & $302(60.4)$ & \\
\hline Ki-67 index (\%) & & & & $<0.001$ \\
\hline$<14$ & $368(47.0)$ & $135(36.7)$ & $233(63.3)$ & \\
\hline$\geq 14$ & $415(53.0)$ & $306(73.7)$ & $109(26.3)$ & \\
\hline Luminal subtype & & & & $<0.001$ \\
\hline Luminal A-like & $221(28.2)$ & $53(24.0)$ & $168(76.0)$ & \\
\hline Luminal B-like & $562(71.8)$ & $388(69.0)$ & $174(31.0)$ & \\
\hline $\mathrm{RS}$ & & & & $<0.001$ \\
\hline $18-25$ & $374(47.8)$ & 115 (30.7) & $259(69.3)$ & \\
\hline $26-30$ & $200(25.5)$ & $140(70.0)$ & $60(30.0)$ & \\
\hline$\geq 31$ & 209 (26.7) & $186(89.0)$ & $23(11.0)$ & \\
\hline
\end{tabular}

Data were analyzed using the $\chi^{2}$ test. Chemo, chemotherapy; BCS, breast conserving surgery; IDC, invasive ductal carcinoma; LVI, lymphovascular invasion; ER, estrogen receptor; PR, progesterone receptor; RS, recurrence score.

achieved. No survival difference was observed between patients receiving chemotherapy and patients not receiving chemotherapy in the RS=26-30 group, who displayed good prognoses after a short follow-up period.
Routine clinicopathological factors associated with RS have been widely studied, including age, tumor grade, PR expression, Ki-67 level and luminal subtype. Patients with high tumor grade $(16,18,19)$ or low PR expression $(16,19)$ are associated 
Table IV. Multivariate analysis of factors associated with chemotherapy in the overall population.

\begin{tabular}{|c|c|c|c|}
\hline Variable & OR & $95 \% \mathrm{CI}$ & P-value \\
\hline Age ( $\leq 50$ years vs. $>50$ years $)$ & 1.53 & $0.69-3.39$ & 0.290 \\
\hline Menstrual status (premenopausal vs. postmenopausal) & 2.55 & $1.62-4.02$ & $<0.001$ \\
\hline Comorbidity (yes vs. no) & 0.52 & $0.34-0.79$ & 0.002 \\
\hline Tumor size ( $>2 \mathrm{~cm}$ vs. $\leq 2 \mathrm{~cm})$ & 1.91 & $1.23-2.98$ & 0.004 \\
\hline Histologic type (non-IDC vs. IDC) & 0.33 & $0.10-1.12$ & 0.076 \\
\hline Tumor grade & & & 0.027 \\
\hline III vs. I/II & 2.35 & $1.25-4.40$ & 0.008 \\
\hline Unknown vs. I/II & 0.92 & $0.27-3.18$ & 0.899 \\
\hline ER status $(<50 \%$ vs. $\geq 50 \%)$ & 1.60 & $0.43-5.95$ & 0.487 \\
\hline PR status $(<20 \%$ vs. $\geq 20 \%)$ & 1.78 & $1.00-3.18$ & 0.052 \\
\hline Ki-67 index ( $\geq 14 \%$ vs. $<14 \%)$ & 2.59 & $1.40-4.81$ & 0.002 \\
\hline Luminal subtype (luminal B-like vs. luminal A-like) & 2.29 & $1.09-4.83$ & 0.029 \\
\hline $\mathrm{RS}$ & & & $<0.001$ \\
\hline $26-30$ vs. $18-25$ & 7.20 & $4.55-11.42$ & $<0.001$ \\
\hline$\geq 31$ vs. $18-25$ & 16.08 & $9.19-28.14$ & $<0.001$ \\
\hline
\end{tabular}

OR, odds ratio; CI, confidence interval; IDC, invasive ductal carcinoma; ER, estrogen receptor; PR, progesterone receptor; RS, recurrence score.

with high-risk RS. The similarities and differences between the $\mathrm{RS}=26-30$ and $\mathrm{RS} \geq 31$ groups have attracted increased attention, which may guide further adjuvant chemotherapy selection (20). Park et al (20) reported that, compared with patients with $\mathrm{RS}=18-25$, patients with $\mathrm{RS}=26-30$ displayed more aggressive tumor characteristics. The present study suggested that patients in the $\mathrm{RS}=26-30$ group displayed higher PR expression (OR, 2.84) and lower Ki-67 index (OR, 1.88) compared with those of patients in the $\mathrm{RS} \geq 31$ group. Moreover, there was no significant difference between the RS=18-25 and =26-30 groups, indicating that patients with $\mathrm{RS}=26-30$ may display similar biological behavior to patients with $\mathrm{RS}=18-25$, and cannot be managed in the same way as patients in the $\mathrm{RS} \geq 31$ group.

$\mathrm{RS}$ has been reported to be the most important independent factor associated with adjuvant chemotherapy usage in patients with $\mathrm{HR}^{+} / \mathrm{HER} 2$-/node- breast cancer (21). The usage of the 21-gene RS testing has significantly reduced chemotherapy administration $(22,23)$. Based on the standard RS risk classification (5), the adjuvant usage rates are 4-7, 30-40 and $>80 \%$ in patients with low-, intermediate- and high-risk RS, respectively $(24,25)$. In the present study, the rates of chemotherapy were $30.7,70.0$ and $89.0 \%$ in the $\mathrm{RS}=18-25$, $=26-30$ and $\geq 31$ groups, respectively. In patients with $\mathrm{RS} \geq 18$, RS displayed the highest adjusting OR value in adjuvant chemotherapy selection ( 7.20 for $\mathrm{RS}=26-30$ and 16.08 for $\mathrm{RS} \geq 31$ vs. patients in the $\mathrm{RS}=18-25$ group) compared with the OR values of other clinicopathological parameters; this could reflect the importance of the 21-gene RS assay over routine clinical parameters. In the TAILORx trial, patients with $\mathrm{RS}=26-30$ were typically categorized into the intermediate-risk RS group, but were recommended chemotherapy, which may have resulted in the high rate of chemotherapy usage in these patients (10).

According to the NCCN guideline, adjuvant endocrine therapy and adjuvant chemotherapy followed by endocrine therapy can be considered for patients in the RS=26-30 group (9). Park et al (20) reported that, in the $\mathrm{RS}=26-30$ group, patients who were younger and displayed grade-III tumors could gain survival benefit from adjuvant chemotherapy. Tsai et al (26) reported that the 70-gene signature could guide adjuvant chemotherapy in patients with $\mathrm{RS}=18-30$. Moreover, a previous study indicated that a nomogram based on routine clinicopathological factors could also predict the probability of chemotherapy recommendation (27). The present study conducted a univariate analysis, which indicated that age, menstrual status, comorbidity, tumor size, histological type, tumor grade, Ki-67 index and luminal subtype were associated with chemotherapy usage in patients with RS 26-30, whereas only age and luminal subtype remained significant in the multivariate analysis. The TAILORx trial observed that patients aged $\leq 50$ years with $\mathrm{RS}=16-25$ could benefit from chemotherapy (12). Williams et al (28) reported that patients aged $<50$ years were more likely to receive adjuvant chemotherapy compared with those aged $>50$ years, regardless of their RS. The Danish Breast Cancer Cooperative Group-77B clinical trial demonstrated that patients with luminal A-like breast cancer did not benefit from adjuvant chemotherapy (hazard ratio=1.06; $\mathrm{P}=0.86$ ) (29). Luminal subtype was included in the nomogram model construction that could predict the usage of adjuvant chemotherapy in patients with $\mathrm{RS}=18-30$ (27). The results of the present study suggested that chemotherapy usage was more common in patients aged $\leq 50$ years vs. $>50$ years, or with luminal B-like vs. luminal A-like tumors in the $\mathrm{RS}=26-30$ group. The effect of clinicopathological parameters on treatment decision had also been confirmed by the updated results of the TAILORx trial, which demonstrated that RS combined with clinical-risk stratification helped to optimize treatment selection (30). 
Table V. Clinicopathological characteristics according to chemotherapy usage in patients with a 21-gene recurrence score of 26-30.

\begin{tabular}{|c|c|c|c|c|}
\hline Variable & Total, n (\%) (n=200) & Chemo, n (\%) $(\mathrm{n}=140)$ & Non-chemo, $n(\%)(n=60)$ & P-value \\
\hline Age (years) & & & & 0.012 \\
\hline$\leq 50$ & $58(29.0)$ & $48(82.8)$ & $10(17.2)$ & \\
\hline$>50$ & $142(71.0)$ & $92(64.8)$ & $50(35.2)$ & \\
\hline Menstrual status & & & & 0.022 \\
\hline Premenopausal & $63(31.5)$ & $51(81.0)$ & $12(19.0)$ & \\
\hline Postmenopausal & $137(68.5)$ & $89(65.0)$ & $48(35.0)$ & \\
\hline Comorbidity & & & & 0.017 \\
\hline No & $109(54.5)$ & $84(77.1)$ & $25(22.9)$ & \\
\hline Yes & $91(45.5)$ & $56(61.5)$ & $35(38.5)$ & \\
\hline Surgery type & & & & 0.173 \\
\hline BCS & $91(45.5)$ & $61(43.6)$ & $30(56.4)$ & \\
\hline Mastectomy & $109(54.5)$ & $79(72.5)$ & $30(27.5)$ & \\
\hline Tumor size (cm) & & & & 0.009 \\
\hline$\leq 2$ & $139(69.5)$ & $90(64.7)$ & $49(35.3)$ & \\
\hline$>2$ & $61(30.5)$ & $50(82.0)$ & $11(18.0)$ & \\
\hline LVI & & & & 0.479 \\
\hline Yes & $10(5.0)$ & $6(60.0)$ & $4(40.0)$ & \\
\hline No & $190(95.0)$ & $134(70.5)$ & $56(29.5)$ & \\
\hline Histological type & & & & 0.001 \\
\hline IDC & $167(83.5)$ & $126(75.4)$ & $41(24.6)$ & \\
\hline Non-IDC & $33(16.5)$ & $14(42.4)$ & $19(57.6)$ & \\
\hline Tumor grade & & & & $<0.001$ \\
\hline $\mathrm{I} / \mathrm{II}$ & $135(67.4)$ & $95(70.4)$ & $40(29.6)$ & \\
\hline III & $34(17.0)$ & $32(94.1)$ & $2(5.9)$ & \\
\hline Unknown & $31(15.5)$ & 13 (41.9) & $18(58.1)$ & \\
\hline ER status (\%) & & & & 0.319 \\
\hline$<50$ & $196(98.0)$ & $136(69.4)$ & $60(30.6)$ & \\
\hline$\geq 50$ & $4(2.0)$ & $4(100.0)$ & $0(0.00)$ & \\
\hline PR status $(\%)$ & & & & 0.151 \\
\hline$<20$ & $75(37.5)$ & $57(76.0)$ & $18(24.0)$ & \\
\hline$\geq 20$ & $125(62.5)$ & $83(66.4)$ & $42(33.6)$ & \\
\hline $\mathrm{Ki}-67$ index $(\%)$ & & & & $<0.001$ \\
\hline$<14$ & $95(47.5)$ & $52(54.7)$ & $43(45.3)$ & \\
\hline$\geq 14$ & $105(52.5)$ & $88(83.8)$ & $17(16.2)$ & \\
\hline Luminal subtype & & & & $<0.001$ \\
\hline Luminal A-like & $49(24.5)$ & $20(40.8)$ & $29(59.2)$ & \\
\hline Luminal B-like & $151(75.5)$ & $120(79.5)$ & $31(20.5)$ & \\
\hline
\end{tabular}

Data were analyzed using the Fisher's exact test or the $\chi^{2}$ test. Chemo, chemotherapy; BCS, breast conserving surgery; LVI, lymphovascular invasion; IDC, invasive ductal carcinoma; ER, estrogen receptor; PR, progesterone receptor.

Previous studies reported that the adjuvant chemotherapy recommendation in $\sim 30 \%$ of cases, irrespective of RS risk stratification, would be modified after the 21-gene assay $(23,25,31)$. In the present study, the treatment recommendation of $54(27.0 \%)$ patients was altered once an RS of 26-30 was identified; among them, 52 patients changed from being chemotherapy not recommended prior to multigene testing to chemotherapy recommended afterwards. A possible explanation may be that $\mathrm{RS}=26-30$ is close to high-risk $\mathrm{RS}$ $(\geq 31)$, and therefore, physicians considered the patients to be at risk in the present study. Furthermore, a high compliance rate of $95.0 \%(190 / 200$ patients) was achieved in the cohort of patients included in the present study after 21-gene RS testing and MDT discussion. Furthermore, the acceptance rate in the 


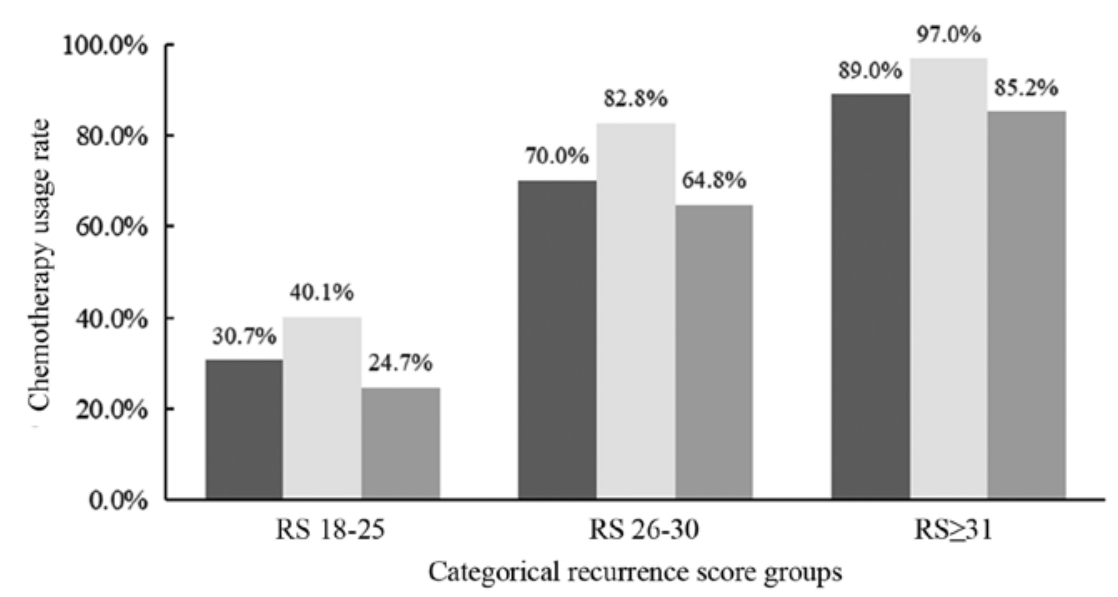

\# All patients $\quad \leq 50$ years $\quad>50$ years

Figure 1. Proportion of chemotherapy usage according to 21-gene recurrence score classification and age.

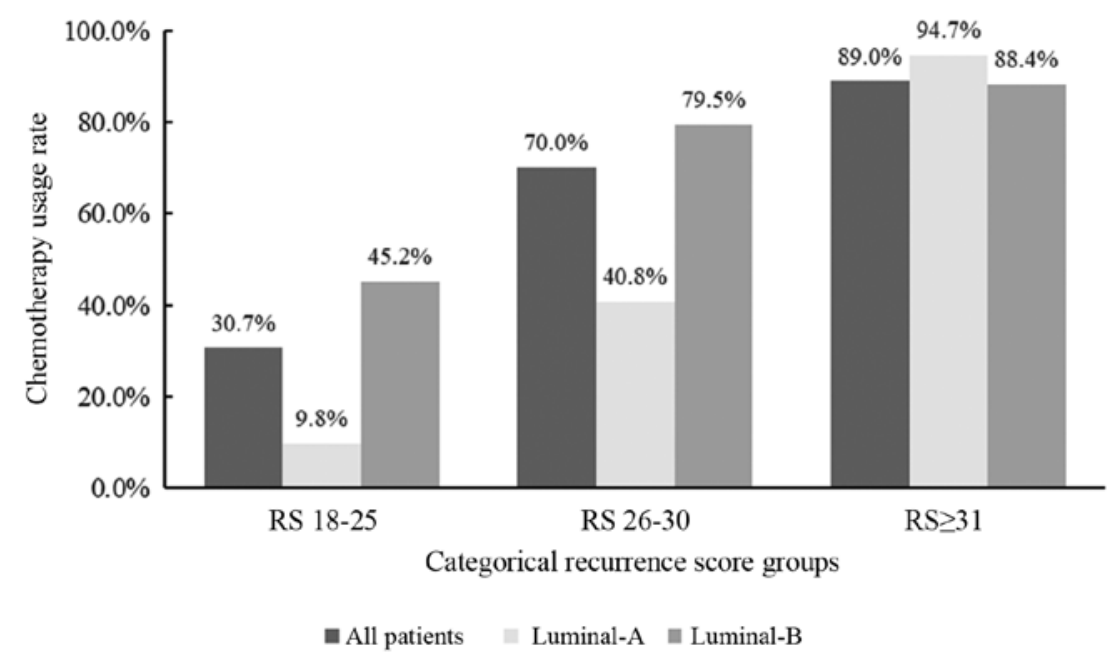

Figure 2. Proportion of chemotherapy usage according to 21-gene recurrence score classification and luminal subtype.

post-RS assay chemotherapy-recommended cohort was $94.5 \%$ (138/146). Kuchel et al (32) also reported that patient decision conflicts decreased after 21 -gene RS testing. Additionally, for patients receiving 70-gene testing, a high compliance rate was reported $(91 \%)$ in terms of adjuvant chemotherapy application (33).

The results from the Surveillance, Epidemiology and End Results (SEER) database revealed a 5-year breast cancer-specific mortality of 2.4 and $4.4 \%$ in $\mathrm{RS}=25-30$ and $>30$ cohorts, respectively (34). The TAILORx study indicated that, for patients with $\mathrm{RS}=11-25$, $=26-30$ and $\geq 31$ who received chemotherapy, the estimated rate of invasive disease-free survival was $97.0,90.5$ and $78.0 \%$ at 5 years, and $92.9,86.3$ and $74.8 \%$ at 9 years, respectively (13). There was no significant survival difference between the three RS groups within the short follow-up period of the present study. However, the SEER data demonstrated that patients with $\mathrm{RS}=26-30$ had inferior breast cancer-specific survival (BCSS; hazard ratio $=1.81$ ) and overall survival $(\mathrm{OS}$; hazard ratio=1.37) compared with those of patients with $\mathrm{RS}=18-25$ (20). When the survival outcome was analyzed according to chemotherapy usage, no benefit from chemotherapy was observed in patients with $\mathrm{RS}=26-30$ in the present study, which was similar to the result reported for the Israeli population (35). Nevertheless, data from the National Cancer Database indicated that there was a $1.8 \%$ absolute decrease in the 5-year mortality risk by chemotherapy in the $\mathrm{RS}=26-30$ population with lymph node-negative disease (hazard ratio=0.68; $\mathrm{P}=0.029$ ) (36). SEER data also suggested that adjuvant chemotherapy was associated with a decreased risk in BCSS (hazard ratio=0.68) and OS (hazard ratio=0.58) (20). The relatively short follow-up time and the small number of recurrence events in the present study may have underestimated not only the long-term real survival difference in different RS stratifications, but also the influence of adjuvant chemotherapy in patients with RS=26-30.

The present study was designed to evaluate the role of 21-gene RS testing in patients with RS 26-30, for whom adjuvant treatment has been unanimous until now. Additionally, the treatment decision change due to 21-gene RS testing was evaluated in these patients, which has been scarcely investigated in previous literature. However, the present study had a number of limitations. Firstly, the follow-up period was short; 
Table VI. Pre- and post-assay chemotherapy decision and actual usage in patients with a 21-gene recurrence score of 26-30.

\begin{tabular}{|c|c|c|c|c|c|c|}
\hline \multicolumn{2}{|c|}{ Post-assay } & \multicolumn{2}{|c|}{ Pre-assay } & \multicolumn{2}{|c|}{ Actual chemo usage } & \multirow[b]{2}{*}{ Adherence to MDT decision } \\
\hline Decision & $\mathrm{N}(\%)$ & Chemo & Non-chemo & Chemo & Non-chemo & \\
\hline Chemo & $146(73.0)$ & 94 & 52 & 138 & 8 & $190 / 200=95.0 \%$ \\
\hline Non-chemo & $54(27.0)$ & 2 & 52 & 2 & 52 & \\
\hline
\end{tabular}

Chemo, chemotherapy; MDT, multidisciplinary team.

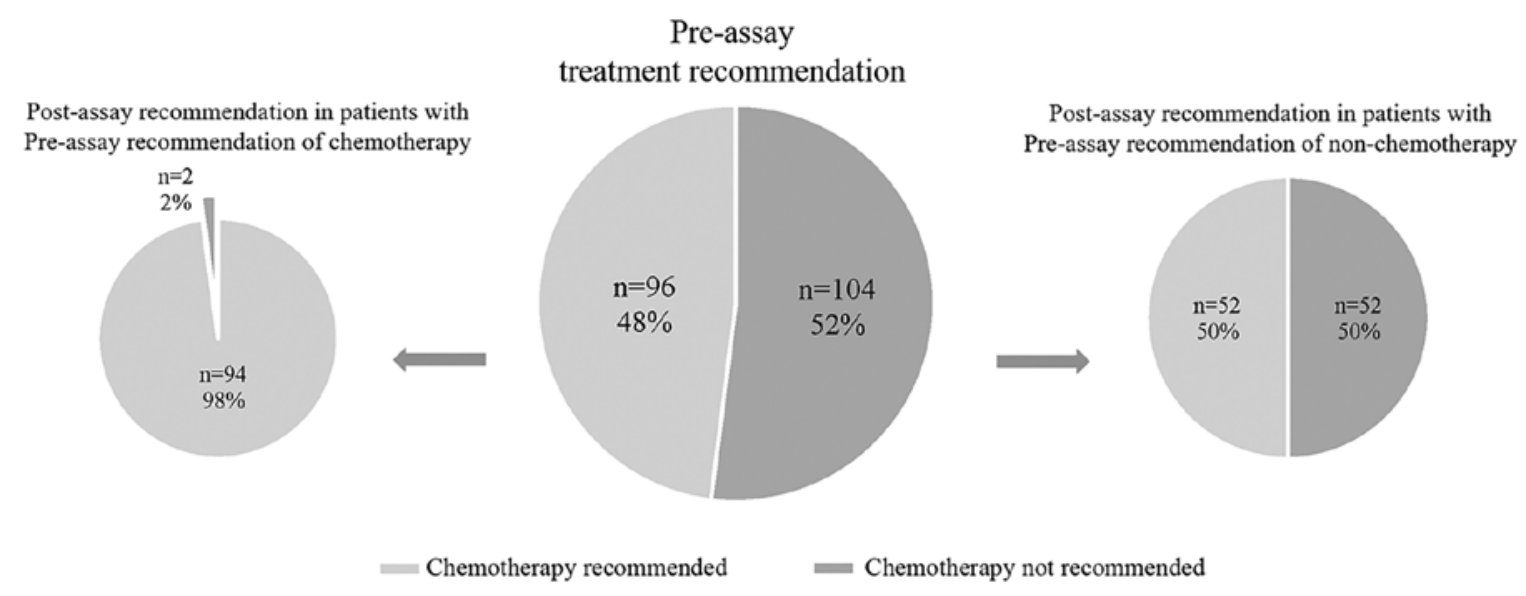

Figure 3. Treatment recommendations before and after the 21-gene assay in patients with a recurrence score of 26-30.

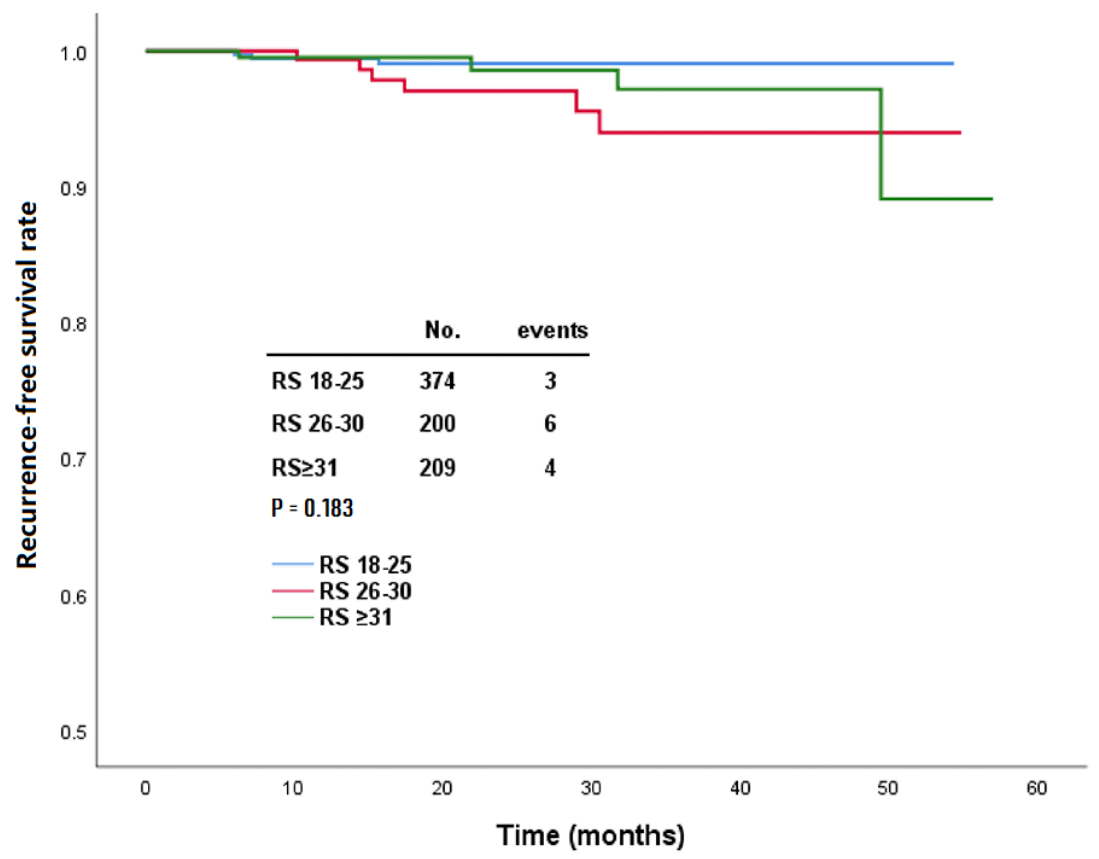

Figure 4. Kaplan-Meier curve of the recurrence-free survival rate according to 21-gene recurrence score classification.

therefore, although the survival benefits due to chemotherapy were greater in the early years and the prognostic effect of the 21-gene RS assay was more robust in the short term, further follow-up is required. Secondly, the similarities and differences in regard to molecular biological features of the
$\mathrm{RS}=26-30$ and other risk groups remain unknown. The expression levels of every single gene in the 21-gene RS panel need to be further compared across the three RS groups. Finally, the retrospective design was subjected to confounding factors, and although multivariate analysis was used to eliminate the 
confounding effect, selection bias may still exist; therefore, the results require cautious interpretation and further validation.

In conclusion, the present study suggested that PR expression was higher and $\mathrm{Ki}-67$ index was lower in the RS=26-30 group compared with those in the $\mathrm{RS} \geq 31$ group, and there was no significant clinicopathological difference between the $\mathrm{RS}=18-25$ and $=26-30$ groups. For patients with $\mathrm{RS}=26-30$, age $\leq 50$ years and luminal B subtype were independently associated with increased chemotherapy usage. The results suggested that the 21-gene RS testing could influence chemotherapy administration and improve the adherence rate of adjuvant treatment. The short follow-up period demonstrated that patients with $\mathrm{RS}=26-30$ displayed promising disease outcomes, and may receive little benefit from adjuvant chemotherapy; however, further evaluation is required.

\section{Acknowledgements}

The authors would like to thank Ms. Yidong Du (Comprehensive Breast Health Center, Ruijin Hospital, Shanghai Jiaotong University School of Medicine) for her contribution during the follow-up and Dr Min Jin (Institute of Health Science Shanghai Institutes of Biological Sciences, Chinese Academy of Sciences) for her help with statistical analysis.

\section{Funding}

The present study was supported by the National Natural Science Foundation of China (grant no. 81772797), the Shanghai Municipal Education Commission-Gaofeng Clinical Medicine Grant Support (grant no. 20172007) and the Shanghai Jiao Tong University School of Medicine-'Guangci Excellent Youth Training Program' (grant no. GCQN-2017-A18).

\section{Availability of data and materials}

The datasets used and/or analyzed during the current study are available from the corresponding author on reasonable request.

\section{Authors' contributions}

JY, XC and KS conceived the study. JY performed the data analysis. JY wrote the manuscript. XC reviewed and edited the manuscript. KS revised the manuscript critically for important intellectual content. JW, OH, JH, LZ, WC and YL collected and interpreted the data. KS and XC acquired the funding. All authors read and approved the final manuscript.

\section{Ethics approval and consent to participate}

All procedures were performed in accordance with the ethical standards of the Ethical Committees of Ruijin Hospital and the Declaration of Helsinki of 1964. The present study was reviewed and approved by the Ethical Committee of Ruijin Hospital.

\section{Patient consent for publication}

Not applicable.

\section{Competing interests}

The authors declare that they have no competing interests.

\section{References}

1. Torre LA, Bray F, Siegel RL, Ferlay J, Lortet-Tieulent J and Jemal A: Global cancer statistics, 2012. CA Cancer J Clin 65: 87-108, 2015

2. Early Breast Cancer Trialists' Collaborative Group (EBCTCG); Peto R, Davies C, Godwin J, Gray R, Pan HC, Clarke M, Cutter D, Darby S, McGale P, et al: Comparisons between different polychemotherapy regimens for early breast cancer: Meta-analyses of long-term outcome among 100,000 women in 123 randomised trials. Lancet 379: 432-444, 2012.

3. Early Breast Cancer Trialists' Collaborative Group (EBCTCG): Effects of chemotherapy and hormonal therapy for early breast cancer on recurrence and 15-year survival: An overview of the randomised trials. Lancet 365: 1687-1717, 2005.

4. Kwa M, Makris A and Esteva FJ: Clinical utility of gene-expression signatures in early stage breast cancer. Nat Rev Clin Oncol 14: 595-610, 2017.

5. Paik S, Shak S, Tang G, Kim C, Baker J, Cronin M, Baehner FL, Walker MG, Watson D, Park T, et al: A multigene assay to predict recurrence of tamoxifen-treated, node-negative breast cancer. N Engl J Med 351: 2817-2826, 2004.

6. Paik S, Tang G, Shak S, Kim C, Baker J, Kim W, Cronin M, Baehner FL, Watson D, Bryant J, et al: Gene expression and benefit of chemotherapy in women with node-negative, estrogen receptor-positive breast cancer. J Clin Oncol 24: 3726-3734, 2006.

7. Goldstein LJ, Gray R, Badve S, Childs BH, YoshizawaC, Rowley S, Shak S, Baehner FL, Ravdin PM, Davidson NE, et al: Prognostic utility of the 21-gene assay in hormone receptor-positive operable breast cancer compared with classical clinicopathologic features. J Clin Oncol 26: 4063-4071, 2008.

8. Albain KS, Barlow WE, Shak S, Hortobagyi GN, Livingston RB, Yeh IT, Ravdin P, Bugarini R, Baehner FL, Davidson NE, et al: Prognostic and predictive value of the 21-gene recurrence score assay in postmenopausal women with node-positive, oestrogen-receptor-positive breast cancer on chemotherapy: A retrospective analysis of a randomised trial. Lancet Oncol 11: 55-65, 2010.

9. Goetz MP, Gradishar WJ, Anderson BO, Abraham J, Aft R, Allison KH, Blair SL, Burstein HJ, Dang C, Elias AD, et al: NCCN guidelines insights: Breast cancer, version 3.2018. J Natl Compr Cancer Netw 17: 118-126, 2019.

10. Sparano JA, Gray RJ, Makower DF, Pritchard KI, Albain KS, Hayes DF, Geyer CE Jr, Dees EC, Perez EA, Olson JA Jr, et al: Prospective validation of a 21-gene expression assay in breast cancer. N Engl J Med 373: 2005-2014, 2015.

11. Gluz O, Nitz UA, Christgen M, Kates RE, Shak S, Clemens M, Kraemer S, Aktas B, Kuemmel S, Reimer T, et al: West German study group phase III planB trial: First prospective outcome data for the 21-gene recurrence score assay and concordance of prognostic markers by central and local pathology assessment. J Clin Oncol 34: 2341-2349, 2016.

12. Sparano JA, Gray RJ, Makower DF, Pritchard KI, Albain KS, Hayes DF, Geyer CE Jr, Dees EC, Goetz MP, Olson JA Jr, et al: Adjuvant chemotherapy guided by a 21 -gene expression assay in breast cancer. N Engl J Med 379: 111-121, 2018.

13. Sparano JA, Gray RJ, Makower DF, Albain KS, Saphner TJ, Badve SS, Wagner LI, Kaklamani VG, Keane MM, Gomez HL, et al: Clinical outcomes in early breast cancer with a high 21-gene recurrence score of 26 to 100 assigned to adjuvant chemotherapy plus endocrine therapy: A secondary analysis of the TAILORx randomized clinical trial. JAMA Oncol 2019 (Epub ahead of print).

14. Lakhani SR, Ellis IO, Schnitt SJ, Tan PH and van de Vijver MJ (eds): WHO classification of tumours of the breast. 4th Edition, Volume 4. IARC WHO Classification of Tumours, 2012.

15. Goldhirsch A, Winer EP, Coates AS, Gelber RD, Piccart-Gebhart M, Thürlimann B and Senn HJ; Panel members: Personalizing the treatment of women with early breast cancer: Highlights of the St Gallen international expert consensus on the primary therapy of early breast cancer 2013. Ann Oncol 24: 2206-2223, 2013. 
16. Wu J, Fang Y, Lin L, Fei X, Gao W, Zhu S, Zong Y, Chen X, Huang $\mathrm{O}, \mathrm{He} \mathrm{J}$, et al: Distribution patterns of 21-gene recurrence score in 980 Chinese estrogen receptor-positive, HER2-negative early breast cancer patients. Oncotarget 8: 38706-38716, 2017.

17. Agarwal GG: Statistics for surgeons-understanding survival analysis. Indian J Surg Oncol 3: 208-214, 2012.

18. Singh K, He X, Kalife ET, Ehdaivand S, Wang Y and Sung CJ: Relationship of histologic grade and histologic subtype with oncotype Dx recurrence score; retrospective review of 863 breast cancer oncotype Dx results. Breast Cancer Res Treat 168: 29-34, 2018.

19. Huang JL, Kizy S, Marmor S, Altman A, Blaes A, Beckwith H, Tuttle TM and Hui JYC: Tumor grade and progesterone receptor status predict 21-gene recurrence score in early stage invasive breast carcinoma. Breast Cancer Res Treat 172: 671-677, 2018.

20. Park S, Han Y, Liu Y, Toriola AT, Peterson LL, Colditz GA, Kim SI, Cho YU, Park BW and Park Y: Adjuvant chemotherapy and survival among patients 70 years of age and younger with node-negative breast cancer and the 21-gene recurrence score of 26-30. Breast Cancer Res 21: 110, 2019.

21. Jasem J, Amini A, Rabinovitch R, Borges VF, Elias A, Fisher CM and Kabos P: 21-Gene recurrence score assay as a predictor of adjuvant chemotherapy administration for early-stage breast cancer: An analysis of use, therapeutic implications, and disparity profile. J Clin Oncol 34: 1995-2002, 2016.

22. Parsons BM, Landercasper J, Smith AL, Go RS, Borgert AJ and Dietrich LL: 21-Gene recurrence score decreases receipt of chemotherapy in ER + early-stage breast cancer: An analysis of the NCDB 2010-2013. Breast Cancer Res Treat 159: 315-326, 2016.

23. Albanell J, Svedman C, Gligorov J, Holt SD, Bertelli G, Blohmer JU, Rouzier R, Lluch A and Eiermann W: Pooled analysis of prospective European studies assessing the impact of using the 21-gene recurrence score assay on clinical decision making in women with oestrogen receptor-positive, human epidermal growth factor receptor 2-negative early-stage breast cancer. Eur J Cancer 66: 104-113, 2016.

24. Orucevic A, Heidel RE and Bell JL: Utilization and impact of 21-gene recurrence score assay for breast cancer in clinical practice across the United States: Lessons learned from the 2010 to 2012 national cancer data base analysis. Breast Cancer Res Treat 157: 427-435, 2016.

25. Carlson JJ and Roth JA: The impact of the oncotype Dx breast cancer assay in clinical practice: A systematic review and meta-analysis. Breast Cancer Res Treat 141: 13-22, 2013.

26. Tsai M, Lo S, Audeh W, Qamar R, Budway R, Levine E, Whitworth P, Mavromatis B, Zon R, Oldham D, et al: Association of 70-gene signature assay findings with physicians' treatment guidance for patients with early breast cancer classified as intermediate risk by the 21-gene assay. JAMA Oncol 4: e173470, 2018.

27. Qu F, Chen X, Fei X, Lin L, Gao W, Zong Y, Wu J, Huang O, He J, Zhu L, et al: A nomogram to predict adjuvant chemotherapy recommendation in breast cancer patients with intermediate recurrence score. Chin J Cancer Res 30: 222-230, 2018.
28. Williams AD, Reyes SA, Arlow RL, Tchou J and De La Cruz LM: Is age trumping genetic profiling in clinical practice? relationship of chemotherapy recommendation and oncotype DX recurrence score in patients aged $<50$ years versus $>/=50$ years, and trends over time. Ann Surg Oncol 25: 2875-2883, 2018.

29. Nielsen TO, Jensen MB, Burugu S, Gao D, Jørgensen CL, Balslev E and Ejlertsen B: High-risk premenopausal luminal a breast cancer patients derive no benefit from adjuvant cyclophosphamide-based chemotherapy: Results from the DBCG77B clinical trial. Clin Cancer Res 23: 946-953, 2017.

30. Sparano JA, Gray RJ, Ravdin PM, Makower DF, Pritchard KI, Albain KS, Hayes DF, Geyer CE Jr, Dees EC, Goetz MP, et al: Clinical and genomic risk to guide the use of adjuvant therapy for breast cancer. N Engl J Med 380: 2395-2405, 2019.

31. Levine MN, Julian JA, Bedard PL, Eisen A, Trudeau ME, Higgins B, Bordeleau L and Pritchard KI: Prospective evaluation of the 21-gene recurrence score assay for breast cancer decision-making in ontario. J Clin Oncol 34: 1065-1071, 2016.

32. Kuchel A, Robinson T, Comins C, Shere M, Varughese M, Sparrow G, Sahu A, Saunders L, Bahl A, Cawthorn SJ and Braybrooke JP: The impact of the 21-gene assay on adjuvant treatment decisions in oestrogen receptor-positive early breast cancer: A prospective study. Br J Cancer 114: 731-736, 2016.

33. Kuijer A, Straver M, den Dekker B, van Bommel ACM, Elias SG, Smorenburg CH, Wesseling J, Linn SC, Rutgers EJT, Siesling S and van Dalen T: Impact of 70-gene signature use on adjuvant chemotherapy decisions in patients with estrogen receptor-positive early breast cancer: Results of a prospective cohort study. J Clin Oncol 35: 2814-2819, 2017.

34. Petkov VI, Miller DP, Howlader N, Gliner N, Howe W, Schussler N, Cronin K, Baehner FL, Cress R, Deapen D, et al: Breast-cancer-specific mortality in patients treated based on the 21-gene assay: A SEER population-based study. NPJ Breast Cancer 2: 16017, 2016.

35. Stemmer SM, Steiner M, Rizel S, Soussan-Gutman L, Ben-Baruch N, Bareket-Samish A, Geffen DB, Nisenbaum B, Isaacs K, Fried G, et al: Clinical outcomes in patients with node-negative breast cancer treated based on the recurrence score results: Evidence from a large prospectively designed registry. NPJ Breast Cancer 3: 33, 2017.

36. Ibraheem AF, Press DJ, Olopade OI and Huo D: Community clinical practice patterns and mortality in patients with intermediate oncotype DX recurrence scores: Who benefits from chemotherapy? Cancer 125: 213-222, 2019.

This work is licensed under a Creative Commons Attribution-NonCommercial-NoDerivatives 4.0 International (CC BY-NC-ND 4.0) License. 